\title{
Erratum to: Gossans, Slates, and the Red and Black Hamlets of Segovia (Spain): Interrelated Geological and Architectural Features
}

\author{
Roberto Oyarzun $^{1,2}$ • José Francisco Martín Duque ${ }^{3,4}$. José F. Barrenechea ${ }^{1,3}$. \\ José Ángel López García ${ }^{1}$
}

Published online: 19 May 2017

(C) The European Association for Conservation of the Geological Heritage 2017

\section{Erratum to: Geoheritage}

DOI 10.1007/s12371-017-0229-0

The original version of this article unfortunately contained a mistake. Figures 4 and 5 were interchanged. The correct versions are given below.

The original article was corrected.

The online version of the original article can be found at http://dx.doi.org/ 10.1007/s12371-017-0229-0

Roberto Oyarzun

oyarzun@ucm.es

1 Departamento de Cristalografía y Mineralogía, Facultad de Ciencias Geológicas, Universidad Complutense de Madrid, 28040 Madrid, Spain

2 Instituto de Geología Aplicada (IGeA), Universidad de Castilla-La Mancha, 13400 Almadén, Spain

3 Instituto de Geociencias (IGEO), CSIC-UCM, 28040 Madrid, Spain

4 Departamento de Geodinámica, Facultad de Ciencias Geológicas, Universidad Complutense de Madrid, 28040 Madrid, Spain

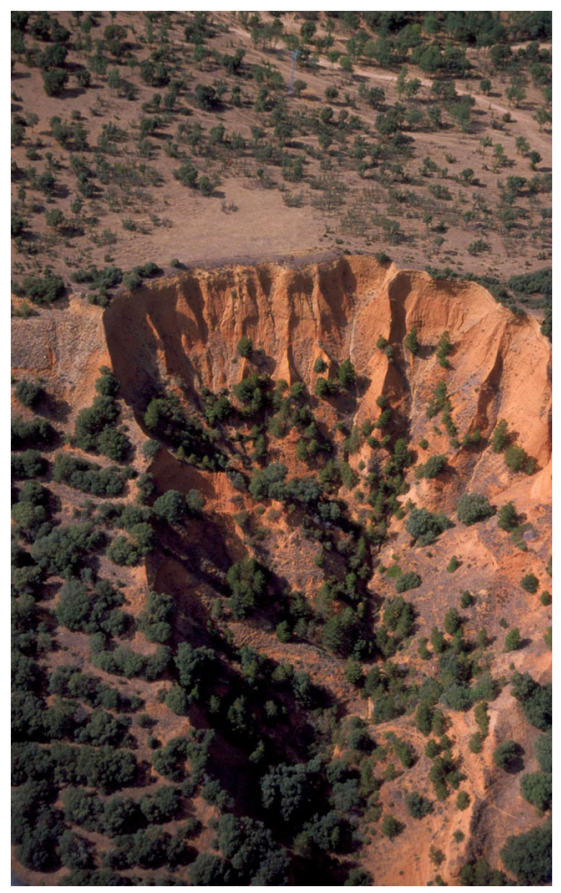

Fig. 4 Detail of a typical gullied slope (head of the gully) in the northern piedmont of the Sierra of Ayllón. The catchment has a usual amphitheater shape, with a pinnate drainage pattern; note the red-brown colors. Photo: Courtesy of Justino Diez 
Fig. 5 a The Silurian "white slates" with strong advanced argillic alteration (bleached slates) and the gossan. b The paleochannel that accommodates the gossan, an erosive feature excavated in the altered slates. c The contact between the gossan and the altered slates; see also the leached oxidized stockwork and individual veins
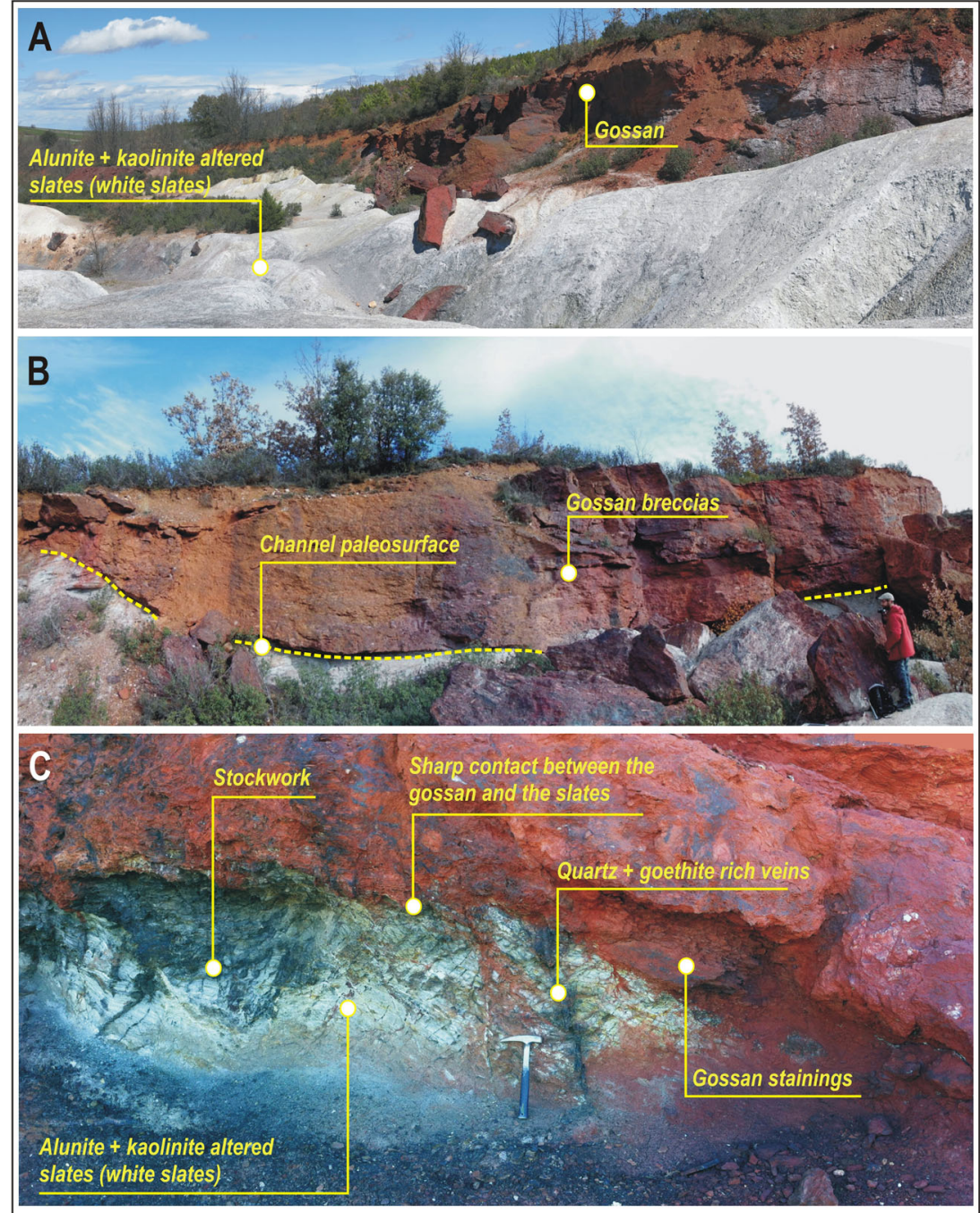